\title{
SISTEM INFORMASI SISWA PKL DAN PSG PADA PT.ASTRA INTERNATIONAL DAIHATSU CIBUBUR
}

\author{
Muhammad Rohman', Agus Darmawan², Nur Alamsyah ${ }^{3}$ \\ ${ }^{1,2,3}$ Universitas Indraprasta PGRI \\ Jl. Raya Tengah No. 80, Kel. Gedong, Kec. Pasar Rebo, Jakarta Timur13760, Jakarta \\ 163mrohman@gmail.com, $\underline{\text { 2agay.unindra08@gmail.com, }}$ ㄹalamcbr11@gmail.com
}

\begin{abstract}
ABSTRAK
Tujuan dari penelitian adalah untuk memudahkan pengelolaan siswa PKL dan PSG yang melakukan On Job Training (OJT) pada PT Astra Daihatsu International Cibubur yang beralamat di Jalan Alternatif Cibubur KM1 No.68 Cimanggis Depok sehingga data yang diproses akan lebih akurat serta mempermudah proses laporan data siswa. Metode penelitian yang digunakan dalam perancangan Sistem Informasi Siswa PKL Dan PSG Pada PT.Astra International Daihatsu Cibubur ini adalah Research and Development dengan metode pengambilan data studi lapangan, yaitu melalui pengamatan langsung, wawancara dengan pihak terkait, dan melakukan dokumentasi untuk mendapatkan informasi yang dibutuhkan. Selain itu, peneliti juga melakukan pengembangan sistem dengan metode Waterfall . Dalam membangun sistem ini, peneliti menggunakan alat bantu perancangan sistem yaitu Diagram Aliran Data (DAD) Konteks, Nol dan Rinci. Sistem informasi informasi ini dapat mempermudah pekerjaan PIC siswa PKL dan PSG dalam mengelola data siswa.
\end{abstract}

Kata Kunci: Sistem Informasi, Siswa PKL dan PSG

\begin{abstract}
The purpose of the study is to facilitate the management of street vendors and PSG students who conduct On Job Training (OJT) at PT Astra Daihatsu International Cibubur which is located at Jalan Alternatif Cibubur KM1 No. 68 Cimanggis Depok so that the processed data will be more accurate and facilitate the process of student data reports. . The research method used in designing the PKL and PSG Student Information System at PT. Astra International Daihatsu Cibubur is Research and Development with field study data collection methods, namely through direct observation, interviews with related parties, and documentation to obtain the required information. In addition, researchers also develop a system using the Waterfall method. In building this system, researchers used system design tools, namely Context, Zero and Detailed Data Flow Diagrams (DAD). This information information system can facilitate the work of PIC for PKL and PSG students in managing student data.
\end{abstract}

Key Word: Information System, students PKL and PSG

\section{PENDAHULUAN}

PT. Astra International memiliki kontribusi sosial yang dijabarkan dalam Public Contribution Roadmap setiap tahunnya. Implementasi kontribusi sosial yang dilakukan berfokus pada empat pilar utama, yaitu Kesehatan, Pendidikan, Lingkungan dan Kewirausahaan. Dalam pilar Pendidikan PT. Astra Internasioanl memiliki program "Astra Untuk Indonesia Cerdas" salah satunya adalah kegiatan SMK Binaan. Terdapat 2.813 SMK diseluruh Indonesia yang mempunyai kesempatan dibina oleh PT. Astra International, salah satunya dibina oleh PT.Astra International Daihatsu Cibubur.

Sejalan dengan itu permintaan tenaga terampil lulusan Sekolah Menengah Kejuruan (SMK) menjadi semakin meningkat. Oleh karena itu, SMK perlu membekali peserta didiknya dengan pengetahuan dan keterampilan yang dibutuhkan dunia kerja dan industri. Seperti ditetapkannya Peraturan Presiden Nomor 8 Tahun 2012 tentang Kerangka Kualifikasi Nasional Indonesia yang semakin menegaskan bahwa SMK harus semakin lebih mendekatkan diri dengan kebutuhan dunia kerja. Salah satu upaya yang harus dilakukan adalah dengan menyelenggarakan program keahlian yang sesuai dengan kebutuhan dunia kerja dan industri agar penyelenggaraan pendidikan di SMK menjadi efektif dan efisien.(International, 2017)

Pada proses perawatan dan perbaikan general repair, PT. Astra International Daihatsu Cibubur memiliki program yang bekerja sama dengan sekolah-sekolah binaan, yang memberikan kesempatan kepada siswanya untuk mengikuti program Praktik Kerja Lapangan (PKL) dan Pembelajaran Sistem 
Ganda (PSG). Dengan adanya program ini PT Astra International Daihatsu Cibubur menerima sejumlah siswa dari sekolahsekolah yang sudah bekerjasama untuk dibina dan diberikan bekal pengalaman kerja.

Terdapat perbedaan antara siswa PKL dan PSG yang ada pada PT Astra International Daihatsu Cibubur, dimana siswa PKL mengikuti program ini hanya selama tiga bulan, sedangkan untuk siswa PSG mengikuti program ini selama dua tahun. Siswa PSG menjalanai program ini dengan metode seminggu di sekolah dan seminggu di perusahaan selama periode dua tahun tersebut.

Pengelolaan manajemen para siswa ini masih banyak sekali kekurangannya sehingga timbul beberapa permasalahan diantaranya yaitu: PIC siswa PKL dan PSG kesulitan ketika mengelola data-data siswa, menngelola absensi siswa, mengelola nilai-nilai siswa, membuat laporan kepada Kepala Bengkel karena masih menggunakan metode manual. Maka dari itu dibutuhkan sebuah Software atau perangkat lunak untuk menunjang dan mempermudah pekerjaan PIC terhadap pengelolaan manajemen para siswa.

Tujuan dari penelitian ini adalah merancang sistem informasi datas siswa PKL dan PSG untuk membantu serta dapat meminimalisasi kesalahan PIC mempermudah ketika pembuatan laporan data siswa PKL dan PSG.

Praktik Kerja Lapangan (PKL) dan Pembelajaran Sistem Ganda (PSG) merupakan salah satu bentuk implementasi secara sistematis dan sikron antara program pendidikan di sekolah dengan program penguasaan keahlian tertentu didunia kerja. Selain itu PKL dan PSG merupakan salah satu kegiatan akademik yang wajib diikuti oleh seluruh siswa / siswi pada Sekolah Menengah Kejuruan (SMK).

Perancangan adalah sebuah proses untuk mendefinisikan sesuatu yang akan dikerjakan dengan menggunakan teknik yang bervariasi serta didalamnya melibatkan deskripsi mengenai arsitektur serta detail komponen dan juga keterbatasan yang akan dialami dalam proses pengerjaannya.(Montreano, 2016)
Sistem informasi merupakan suatu sistem di dalam suatu organisasi yang bersifat mengakomodir dan kegiatan strategi dari suatu organisasi serta menyediakan pihak luar tertentu dengan laporan-laporan yang diperlukan (Hutahaean, 2014).

Berdasarkan penjelasan di atas, dirancanglah Sistem Informasi Siswa PKL Dan PSG Pada PT.Astra International Daihatsu Cibubur. Yang keguanaannya didapat adalah memberi kemudahan kepada PT Astra International Daihatsu Cibubur khususnya PIC PKL dan PSG dalam melakukan pengeloaan siswanya, serta memberi kemudahan untuk pembuatan laporan.

\section{METODE PENELITIAN}

Metode penelitian dan pengembangan atau Research and Development adalah metode penelitian yang digunakan untuk menghasilkan produk tertentu, dan menguji keefektifan produk tersebut. Adapun produk tersebut tidak selalu berbentuk benda atau perangkat keras (hardware), seperti buku, alat tulis, dan alat pembelajaran lainnya. Akan tetapi, dapat pula dalam bentuk perangkat lunak (software) (Sugiyono, 2012).

Langkah-langkah pengembangan sistem yang digunakan penulis dalam pengembangan Sistem Informasi Siswa PKL Dan PSG Pada PT.Astra International Daihatsu Cibubur. dengan menggunakan metode pengembangan model waterfall. Model air terjun menyediakan pendekatan alur hidup perangkat lunak secara urut dimulai dari analisis, desain, pengkodean, pengujian, dan tahap support (Sukamto \& Shalahuddin, 2013).

Rancangan kegiatan dimulai pada Bulan Maret 2021 dengan kunjungan langsung ke lapangan untuk mencatat hal-hal penting sesuai dengan masalah, lalu melakukan wawancara dengan Bapak Agustinus Karyono selaku Kepala Bengkel PT Astra International Daihatsu Cibubur.

Bahasa Pemrograman yang digunakan adalah java. Java merupakan bahasa pemograman yang berorientasi objek untuk pengembangan aplikasi mandiri, aplikasi berbasis internet, aplikasi untuk perangkat pintar yang dapat berkomunikasi lewat internet/jaringan 
komunikasi dan merupakan bahasa pemrograman yang dikembangan dari bahasa pemrograman $\mathrm{C}++$.(Haryanto, 2011).

Netbeans merupakan sebuah aplikasi Integrated Development Environment (IDE) yang menggunakan bahasa pemograman java dari Sun Microsystems yang berjalan diatas swing, dimana sekarang banyak digunakan sebagai editor berbagai bahasa pemograman (Nofriadi, 2015).

MySQL adalah sebuah program database yang mampu menerima dan mengirimkan datanya dengan super cepat dan juga termasuk dalam sistem manajemen basis data SQL (Database Management System) atau dikenal juga dengan DBMS yang multithread dan multi-user (Yudhanto \& Purbayu, 2014).

Aplikasi pengembang yang digunakan adalah Xampp. XAMPP adalah suatu software yang mendukung banyak sistem operasi yang juga bersifat open source yang merupakan pengembangan dari LAMP (Linux, Apache, MySQL, PHP dan Perl) (Purbadian, 2016).

\section{HASIL DAN PEMBAHASAN}

Berdasarkan hasil penelitian, peneliti memberikan analisis permasalahan dari sistem pengelolaan data sebagai berikut.

1. Data masukan berupa identitas siswa dan identitas sekolah masih belum terkomputerisasi dengan baik, yang menyulitkan PIC untuk menemukan data yang ingin dicari bila diperlukan

2. Data masukan perlu dipilah kembali menjadi data yang lebih rinci disesuaikan dengan tingkat kebutuhan untuk data tersebut dikelola oleh PIC ketika ingin digunakan

3. Data keluaran untuk laporan data siswa PKL dan PSG belum ada karena pelapororan masih menggunakan sistem manual menggunakan kertas atau manual.

Berdasarkan masalah yang terdapat pada PT Astra International Daihatsu Cibubur, penulis memberikan beberapa alternatif penyelesaian masalah sebagai berikut.

1. Merancang sistem informasi yang mudah dipahami sehingga dapat menampilkan informasi data alat kesehatan secara cepat dan tepat.
2. Merancang sistem informasi manajemen data siswa dengan sistem basis data secara relasional yang dapat diatur hak aksesnya.

3. Merancang database untuk data alat kesehatan dan data pelanggan sehingga penyimpanan data tidak menggunakan media kertas lagi melainkan berupa database menggunakan harddisk atau penyimpanan elektronik lainnya.

\section{Diagram Konteks Sistem Yang Diusulkan}

Berikut adalah gambaran sistem yang diusulkan untuk PT Astra International Daihatsu Cibubur:

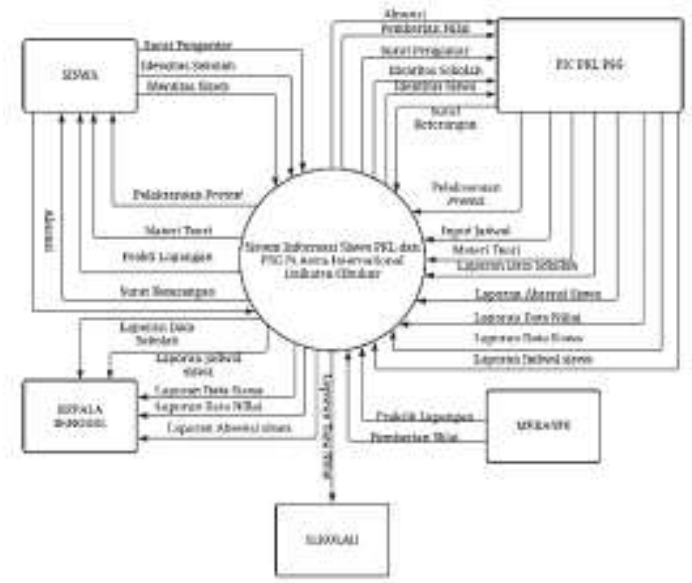

Gambar 1. Diagram Konteks Sistem yang Diusulkan

\section{Diagram Nol Sistem yang Diusulkan}

Diagram nol merupakan gambaran proses sistem berjalan pada sistem penjualan yang menggambarkan tahap-tahap proses dari diagram konteks, yaitu:

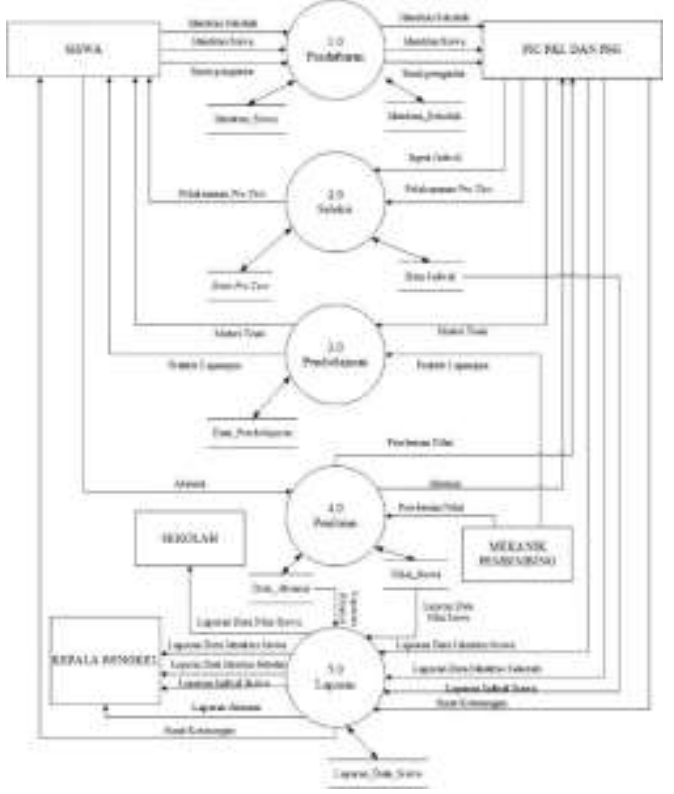

Gambar 2. Diagram Nol Sistem 


\section{Entity Relationship Diagram (ERD)}

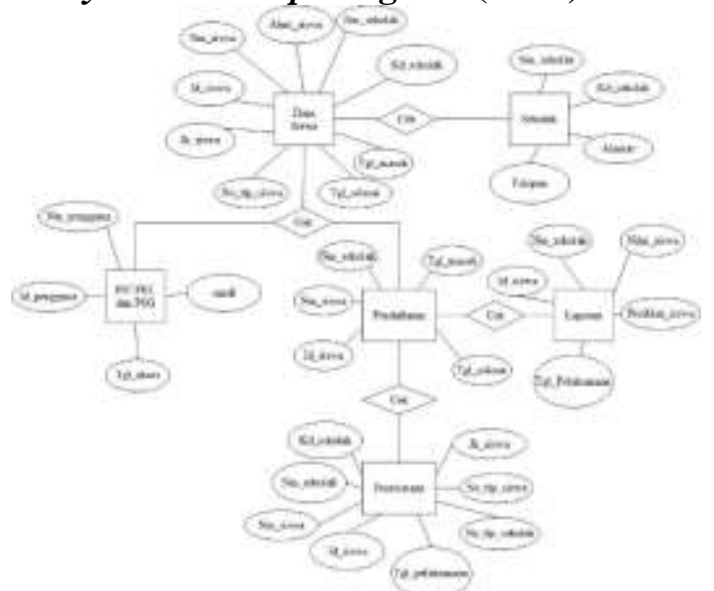

Gambar 3. ERD

\section{Normalisasi Tahap Pertama (1NF)}

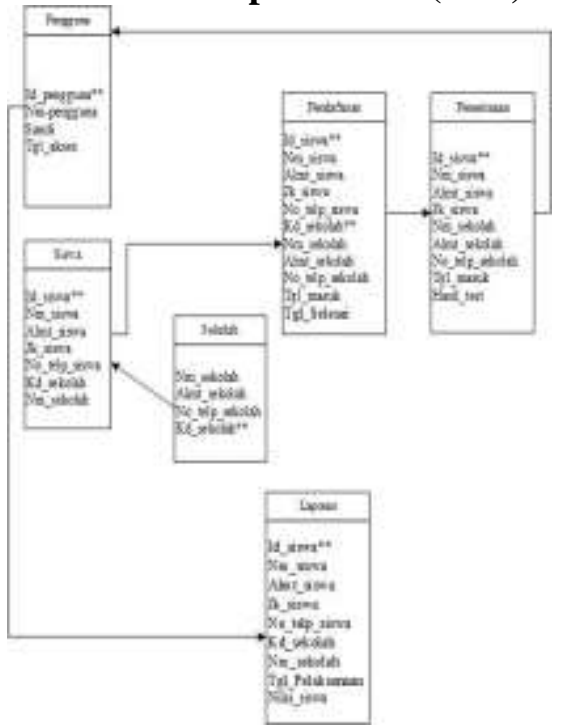

Gambar 4. Normalisasi Tahap Pertama (1NF)

\section{Normalisasi Tahap Kedua (2NF)}
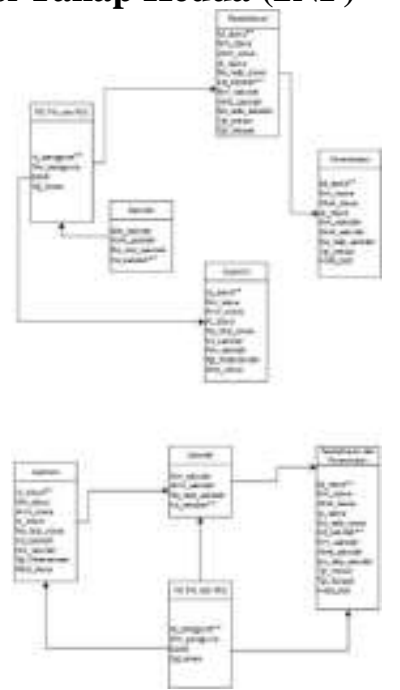

Gambar 5. Normalisasi Tahap Kedua (2NF)
Tampilan Menu Login

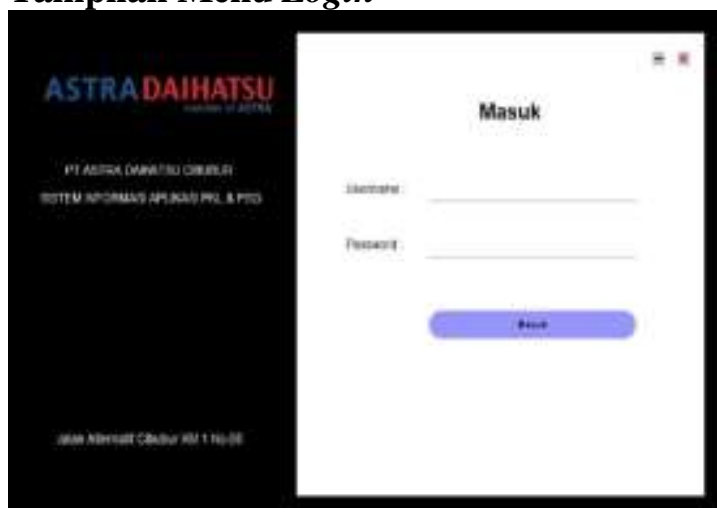

Gambar 6. Tampilan Menu Login

Tampilan menu login digunakan sebagai kata kunci sebelum memasuki program utama. Admin memasukkan username dan password yang sesuai dengan hak akses. Jika username dan password sesuai, akan masuk ke tampilan menu utama.

\section{Tampilan Menu Data Siswa}

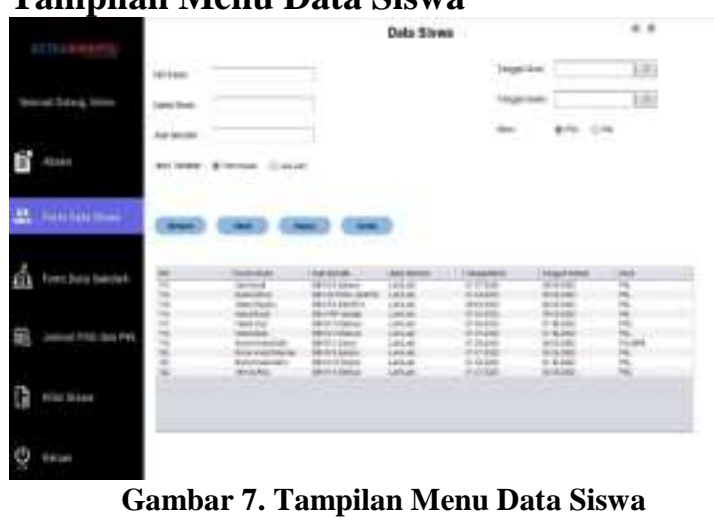

Tampilan menu data siswa untuk memasukan dan menampilkan data dan identitas siswa.

\section{Tampilan Data Nilai Siswa}

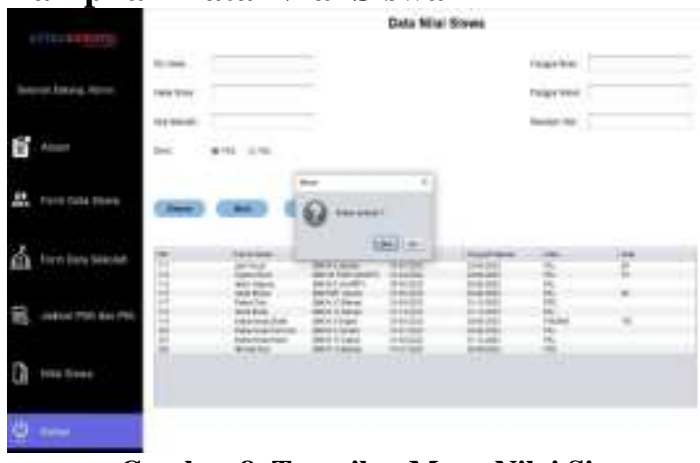

Gambar 8. Tampilan Menu Nilai Siswa

Tampilan menu data nilai siswa untuk memasukan dan menampilkan data nilai siswa. 


\section{Tampilan Jadwal Siswa}

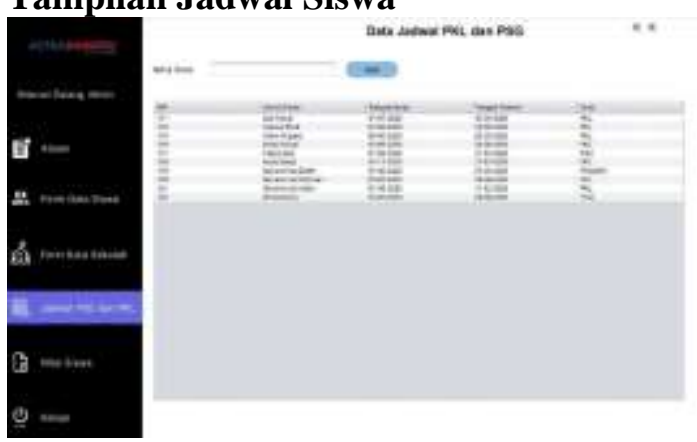

Gambar 9. Tampilan Jadwal Siswa

Tampilan menu jadwal siswa untuk menampilkan data jadwal kegiatan siswa selama mengikuti kegiatan di bengkel.

\section{Tampilan Menu Absensi}

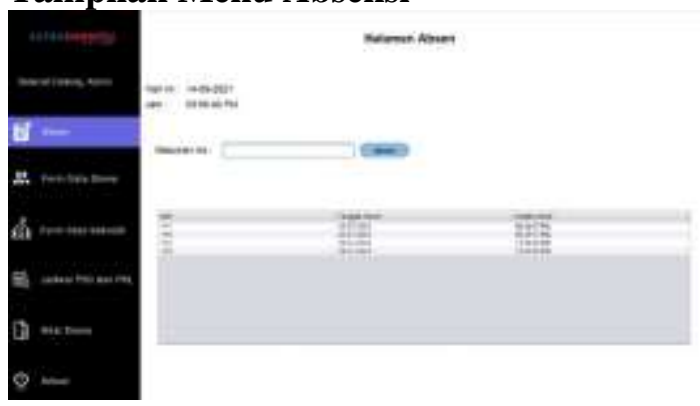

Gambar 10. Tampilan Menu Absensi

Tampilan menu absensi untuk memasukan data absensi siswa dan mencetak laporan data absensi siswa.

\section{Tampilan Laporan Data Siswa}

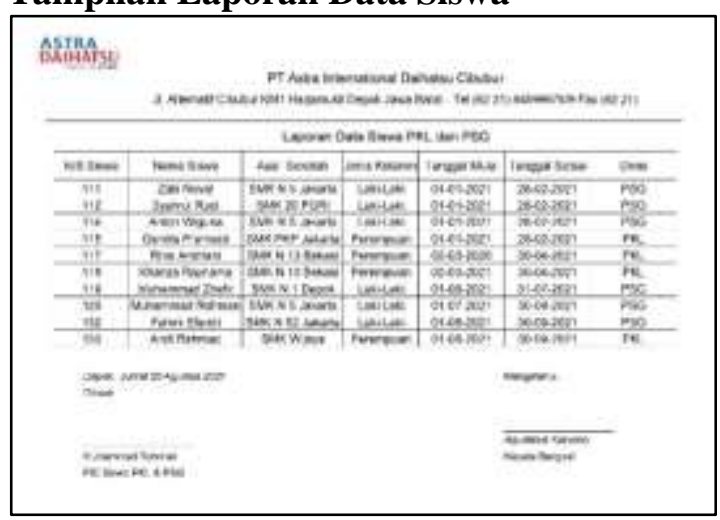

Gambar 11. Tampilan Laporan Data Siswa

Laporan Data Siswa berfungsi untuk menampilkan laporan data-data siswa yang akan dilaporkan ke Kepala Bengkel.
Tampilan Laporan Data Sekolah

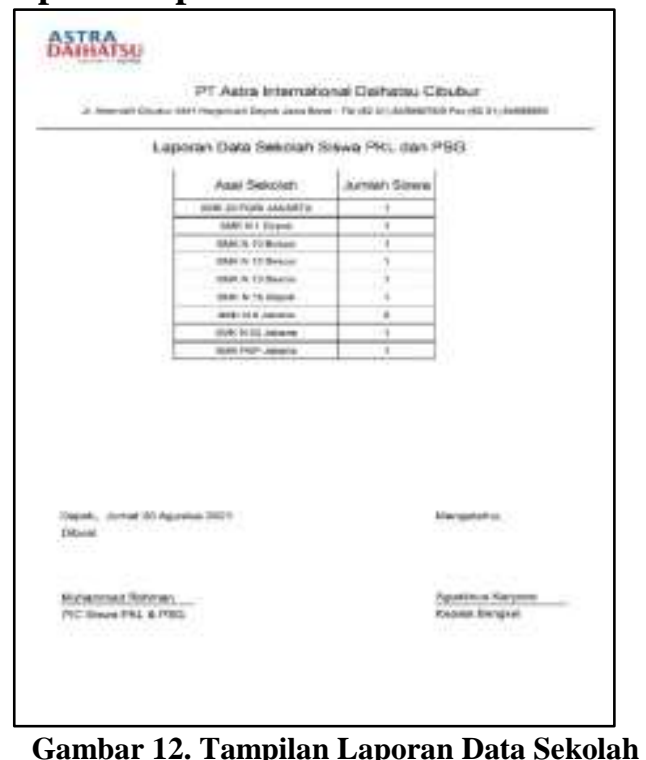

Laporan Data Sekolah berfungsi untuk menampilkan laporan data-data sekolah siswa yang akan dilaporkan ke Kepala Bengkel.

Tampilan Laporan Data Nilai Siswa

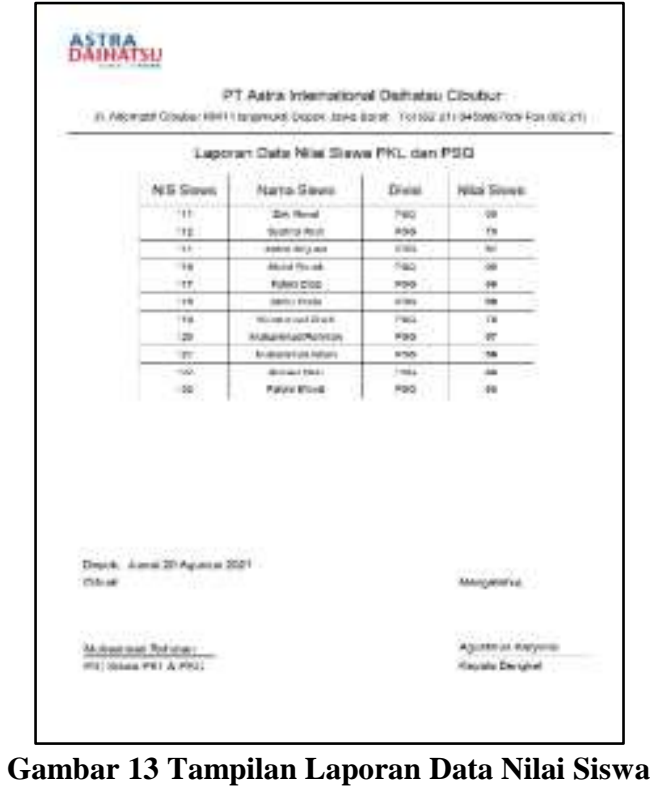

Laporan Data Nilai siswa berfungsi untuk menampilkan data nilai siswa juga sebagai lampiran bukti penilaian siswa yang akan di laporkan ke pihak Sekolah 
Tampilan Laporan Absen Siswa

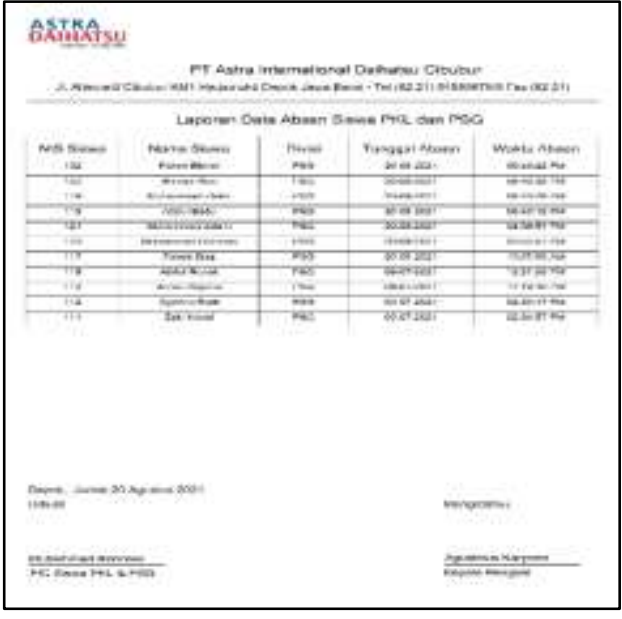

Gambar 14. Tampilan Laporan Absen Siswa

Laporan Absensi siswa berfungsi untuk menampilakan laporan data absensi siswa untuk dilaporkan ke Kepala Bengkel dan pihak Sekolah.

\section{Tampilan Surat Keterangan}

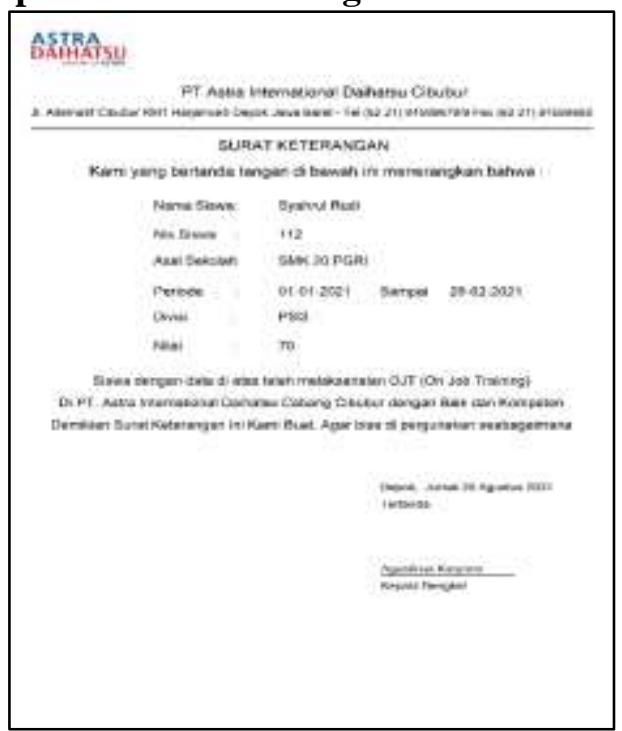

Gambar 15. Tampilan Surat Keterangan

Surat Keterangan adalah surat yang dikeluarkan perusahaan dan diberikan kepada siswa sebagai bukti bahwa siswa tersebut pernah mengikuti kegiatan PKL dan PSG pada PT Astra International Daihatsu Cibubur

\section{SIMPULAN DAN SARAN}

Dari penyusunan dan pembuatan aplikasi sistem informasi siswa PKL dan PSG ini, simpulan yang dapat diambil sebagai adalah : Aplikasi sistem informasi siswa PKL dan PSG ini dapat memberikan kemudahan PIC dalam proses pengelolaan data siswa yang melakukan kegiatan OJT pada PT Astra
International Daihatsu Cibubur. Selain itu pelayanan dari PIC terhadap siswa PKL dan PSG menjadi lebih baik karena sudah terkomputerisasi dengan baik. Lalu dengan adanya sistem aplikasi sistem informasi siswa PKL dan PSG ini, dapat membuat proses laporan data siswa dari PIC ke atasan menjadi lebih cepat efektif dan efisien.

Sejalan dengan sistem yang penulis buat maka penulis dapat memberi saran yaitu perlu perawatan dan pengembangan lebih lanjut agar program ini dapat memberikan pelayanan yang lebih baik dan maksimal, serta aplikasi ini dapat direalisasikan pada cabang Astra Daihatsu yang lain. Dan perlu pengembangan pada sistem laporan sehingga laporan yang dihasilkan dapat terhubung antara sistem komputer satu dan komputer lainnya tanpa harus membuat laporan cetak.

Hasil penelitian ini selaras dengan hasil penelitian yang menyimpulkan bahwa dengan adanya sistem pengajuan klaim kendaraan secara online, kebutuhan user dan pengelola dapat dimudahkan dalam pendaftaran dan pengelolan data di mana pun dan kapan pun tanpa memakan waktu yang lama (Sujarwo et al., 2020).

\section{UCAPAN TERIMAKASIH}

Terimakasih penulis ucapkan untuk PT Astra International Daihatsu Cibubur beserta jajarannya yang telah memberikan bantuan dan izin sehingga penelitian ini terlaksana dengan baik.

\section{DAFTAR PUSTAKA}

Haryanto, B. (2011). Esensi-esensi Bahasa Pemrograman Java. Andi.

Hutahaean, J. (2014). Konsep Sistem Informasi. Cv Budhi Utama.

International, A. (2017). Corporate Social Responsibility Astra. https://www.astra.co.id/CSR

Montreano, D. (2016). Perancangan Sistem Informasi PKL Dan Skripsi yang Mampu Mengukur Waktu Penyelesaian Pengajuan Surat Tugas Pembimbing. Bina Teknika, 12(2), 253-260.

Nofriadi. (2015). Java Fundamental Dengan Netbeans 8.0.2. DeePublish.

Purbadian, Y. (2016). Trik Cepat Membangun 
Aplikasi Berbasis Web dengan

Framework CodeIgniter. Andi Offset.

Sugiyono. (2012). Metode Penelitian

Kuantitatif Kualitatif dan $R \& B$.

Alfabeta.

Sujarwo, A., Sari, A. M., Lestari, R., \& Yani,

D. (2020). Sistem Informasi Pengajuan

Klaim Asuransi Kendaraan Berbasis

Web Menggunakan UML. Jurnal Sistem

Komputer Dan Informatika (JSON),

1(3),

294.

https://doi.org/10.30865/json.v1i3.2197

Sukamto, R. A., \& Shalahuddin, M. (2013). Analisa dan Desain Sistem Informasi. Andi Offset.

Yudhanto, Y., \& Purbayu, A. (2014). Toko Online dengan PHP dan MySQL (Cara mudah dan praktis bagi pemula membuat toko online dari nol). PT Elex Media Komputindo. 